\title{
Educación retórica y filosófica: algunos vínculos entre Aristófanes y Eurípides ${ }^{1}$
}

Rhetorical and Philosophical Education: Some Links between Aristophanes and Euripides

\author{
David GARCía PÉREZ \\ Centro de Estudios Clásicos, IIFL, Universidad Nacional Autónoma de México \\ hyperion0z@yahoo.com
}

\begin{abstract}
Resumen: Considerando los juicios literarios y educativos de Aristófanes sobre el valor de la poesía, en general, y de la tragedia, en particular, se analizan algunos casos representativos en los que se evidencia la educación retórica plasmada en las tragedias de Eurípides. El contenido retórico puesto en acción a través de la dramaturgia griega era motivo de aprendizaje para los receptores. La retórica y su vínculo natural con la sofística, una forma de la filosofía, lleva al punto en el que los contenidos trágicos bajo la estructura retórica fueran también vehículo educativo en la gran escuela que significó el teatro ateniense.
\end{abstract}

\begin{abstract}
Considering the literary and educative ideas of Aristophanes about the value of poetry in general, and in the Tragedy in particular some representative cases are analyzed in which the rhetorical education reflected in the tragedies by Euripides is evident. The rhetorical content put into action through the Greek drama was a matter of learning for the receptors. The Rhetoric and the Sophistry natural link carries to the point that the tragic content in the rhetorical form is also considered an educational vehicle in the great school it meant the Athenian theater.
\end{abstract}

PALABRAS ClAVE: Aristófanes, educación, Eurípides, filosofía, retórica.

KEY WORDS: Aristophanes, Education, Euripides, Philosophy, Rhetoric.

RECIBIDO: 7 de abril de 2015 - ACEPTADO: 21 de agosto de 2015.

En los tiempos que corren actualmente, permea la idea de que la educación, en sus diferentes niveles, debe centrarse en lo que sea útil para obtener resultados materiales, concretos e inmediatos: todo lo que implique cierta "inversión" de tiempo en razón de un proceso reflexivo resulta improcedente de acuerdo con la visión utilitaria de la pedagogía posmoderna. ${ }^{2}$ Este concepto priva en los programas de estudio en los

${ }^{1}$ Proyecto DGAPA, PAPITT IN401615, “Crítica y teoría literarias de la Antigüedad clásica: de Homero a Dante Alighieri”.

${ }^{2}$ Cf. Laudo Castillo, 2011, pp. 45-68. 
que las cuestiones referentes a la literatura - en general a las Humanidades - ocupan un lugar muy secundario y sólo bajo el pretexto de ofrecer un cierto "bagaje cultural" a los estudiantes para que, si bien progresa el asunto, conozcan algunos nombres y obras que el lucro comercial del canon preconiza. Los temas relacionados con la lectura y la escritura se conciben como habilidades simples y llanas que deben estar dispuestas para fines utilitarios que se reducen al simple acto comunicativo, como el descrito profética y acertadamente por George Orwell en su novela 1984, en cuanto que conducen al sujeto a la enajenación:

Saber y no saber, ser consciente de la verdad plena, mientras se cuentan mentiras cuidadosamente construidas, sostener simultáneamente dos opiniones que se anulan, porque se sabe que son contradictorias y se cree en ambas para usar la lógica contra la lógica, para repudiar la moral mientras se apela a ella. ${ }^{3}$

La lectura deviene en un proceso de interpretación mecánica y mediata de los signos, sin que exista una reflexión del contenido. Esta situación cultural se agudiza con respecto al del desarrollo de la tradición clásica: la lectura de los clásicos griegos y latinos resulta en términos generales obsoleta para las políticas educativas actuales, mal orientadas sólo por este motivo. Así, se entiende que leer es una actividad útil para obtener información que se agota en el mismo momento en que se lleva a cabo su proceso, esto es, no hay reflexión en la lectura y, menos aún, permanencia de los contenidos, pues todo aspecto retórico, filosófico o estético, por ejemplo, es irrelevante de acuerdo con las "necesidades" comunicativas que la modernidad y sus secuelas enarbolan en relación con la lengua y la literatura en torno a la preservación, transmisión y generación de conocimiento. Marc Fumaroli, filólogo francés, sentencia

${ }^{3}$ Orwell 2003 (1949), p. 120: "To know and not to know, to be conscious of complete truthfulness while telling carefully constructed lies, to hold simultaneously two opinions which cancelled out, knowing them to be contradictory and believing in both of them, to use logic against logic, to repudiate morality while laying claim to it [...]". Salvo indicación contraria, las traducciones son nuestras. Adviértase el contenido "sofístico" en las palabras e imágenes de Orwell. Sobre el argumento "saber o no saber",

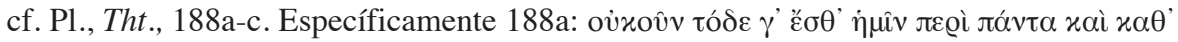

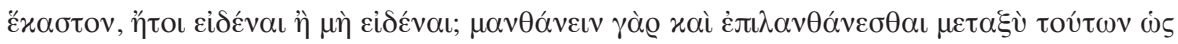

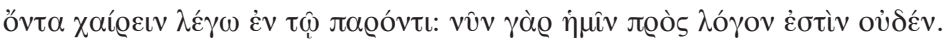


que la televisión, sustituta de los padres, forma parte del problema educativo que margina la lectura, y en ese sentido se observa una coincidencia con Orwell, pues la telepantalla (telescreen) en ambos contextos, el literario y el educativo, es uno de los motores de la precarización de la acción y del resultado de leer en sentido amplio:

La marginalización de los clásicos en la educación explica la reducción de las capacidades de la memoria y atención, pero es, sobre todo, la consecuencia del triunfo de una antieducación muy precoz y general: la impregnación, desde la tierna infancia, de las imágenes pobres y ruidosas del zapping televisivo. La pantalla de televisión es la nueva niñera, la providencia de hogares divididos, o de padres ocupados lejos del hogar. ${ }^{4}$

Las reflexiones de Fumaroli en La educación de la libertad constituyen una defensa de la cultura clásica en su más amplia comprensión y preciso: es trabajo del clasicista atender las expresiones atomizadas y desacertadas de lo que este pensador denomina "revolución cultural y comunicacional" para poder incidir en el camino que ha tomado la educación de los niños y de los jóvenes en la era posmoderna, pues de no ser así las "democracias comerciales" asumen el poder para decidir que, bajo los conceptos de "cultura y comunicación", mal entendidos y aplicados con fines estrictamente utilitarios, se sustituye a los clásicos en el proceso educativo, sobre todo el que corresponde a la etapa de formación de la juventud. ${ }^{5}$

Ahora bien, si se entrelazan los problemas indicados por Orwell y Fumaroli en la coincidencia del aprendizaje reflexivo que proporciona el lenguaje razonado, se puede observar que en diversos momentos del devenir humano se han dado cavilaciones y advertencias semejantes, teniendo en la mira los componentes propios de cada contexto. Una de las discusiones suscitadas en el periodo clásico de la antigua Grecia consistió precisamente en el modo en que se debía educar a los niños y a los jóvenes, sobre todo a estos últimos, pues podían ser rehenes, según algunos pensadores de aquella época, de los sofistas, los primeros maestros de Occidente en el sentido profesional del término, quienes, de acuerdo con Platón, andaban a la caza de los jóvenes ricos para venderles sus en-

\footnotetext{
${ }^{4}$ Fumaroli 2008, p. 8.

${ }^{5}$ Cf. ib., pp. 7, 9 y 20.
} 
señanzas. ${ }^{6}$ Con las distancias guardadas del caso, aquella discusión, sus preocupaciones y afanes son materia propositiva para el tema de la educación de nuestros días en relación con la retórica y la filosofía. Desde esta perspectiva, Aristófanes fue quizás uno de los primeros poetas en la tradición literaria occidental en pensar críticamente a su sociedad, a los poetas de su momento y la utilidad que éstos redituaban a la democrática polis ateniense (V-IV a. C.), teniendo en cuenta la visión de la educación "tradicional" frente a la "novedad" de los sofistas y considerando el valor de la poesía junto con las cualidades educativas vinculadas a ella. Tal pensamiento radica en la trascendencia con la que se apreciaba a la poesía en ese momento como base necesaria para la educación del ciudadano: instruir al polites era tarea, también, del poietés en la medida en que la poesía hacía al sujeto más útil para la polis. Así, para los griegos de la época democrática, tal como se colige de Aristófanes, la poesía tenía una finalidad pragmática, pues en ella se condensaba la política, la ética y la apreciación de la belleza de la palabra:

ESQUILO: Respóndeme: ¿por qué motivo es necesario admirar a un hombre que sea poeta?

EURÍPIDES: Porque es hábil y buen consejero, y porque nosotros hacemos mejores a los hombres en relación con la polis. ${ }^{7}$

En efecto, por medio del concepto de una poesía útil en términos de la educación política hay que advertir la crítica del poeta cómico a los sofistas, en Nubes, ${ }^{8}$ su relación con la retórica y el homenaje crítico-literario a los tres trágicos, Esquilo, Sófocles y Eurípides, en Ranas, ${ }^{9}$ todo ello bajo un concepto de paideia y, en general, la finalidad de la paideia retórica, exposición que permea prácticamente todo el corpus aristofá-

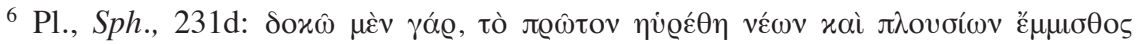

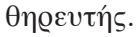

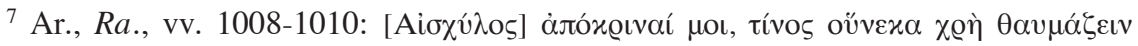

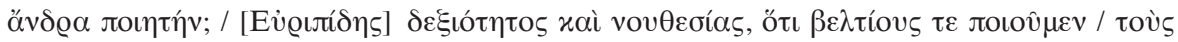

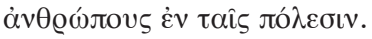

${ }^{8}$ Aristófanes representó Nubes en las Dionisias del 423 a. C. y obtuvo el tercer puesto, detrás de Cratino y de Amipsias.

${ }^{9}$ Eurípides murió en 406 a. C.; al poco tiempo falleció Sófocles; Aristófanes representó Ranas en las Leneas del 405 a. C.
} 
nico. ${ }^{10}$ Si la política es una cualidad de todos los hombres, un elemento esencial que los distingue y aparta del resto de los animales y que es el punto de partida para la convivencia que da origen a las poleis, ${ }^{11}$ entonces el consenso que se produce por medio de la argumentación, de la palabra transformada en retórica, es un proceso necesario para dirimir los conflictos particulares y colectivos. La oposición de pareceres tuvo en el teatro un ejercicio retórico que vinculaba distintas formas discursivas.

Aristófanes presenta en Nubes dos bloques del conocimiento: por una parte la ciencia especulativa (astronomía, meteorología, geología, etc.) y, por otra, la retórica. Vista de este modo, la disposición del conocimiento se concentra en un solo lado todo aquello que tiene que ver con la palabra, si se entiende por retórica una filosofía del lenguaje en sentido amplio y preciso: una parte de la juventud ateniense de la democracia aspiraba a una educación superior en la que la retórica era prácticamente el núcleo de todo aprendizaje. Sin embargo, la caricaturización que Aristófanes hace del joven Fidípides, afecto a los caballos y a la pereza, coloca la crítica en la estructura extremo y fuera de lugar de la argumentación que aprende quien asiste a las clases de los sofistas. En el mundo del revés que distingue a la comedia aristofánica, los hijos se vuelven contra los padres, pero no de una manera mediato y simple, ${ }^{12}$ sino a través del argumento retórico que muestra, efectivamente, que el joven sabe manejar el lenguaje de acuerdo con su particular punto de vista, a pesar de que puede estar equivocado en la pretendida finalidad de sus palabras y de sus pensamientos:

FIDíPIDES: Dime entonces, ¿no es justo que también yo sea benevolente contigo de la misma manera y te golpee, puesto que en eso consiste ser benévolo, en golpear? Pues, ¿cómo es posible que tu cuerpo esté libre de golpes y el mío no? Vaya, también yo soy libre por naturaleza. Los hijos lloran, ¿crees que el padre no debe llorar? Tú afirmas que hay que considerar que esa acción no es propia del hijo; pero yo podría contradecirte: los viejos son dos

${ }^{10}$ Cf. López Eire 2000, pp. 141-190.

${ }^{11} \mathrm{Pl}$., Prot., 323a.

${ }^{12}$ Cf. Cavallero 2006, p. 99; p. 101: "el error [de Estrepsíades] fue darle a su hijo herramientas para dominarlo; quizás, dado que él mismo obligó a su hijo a instruirse, más exactamente el error fue pensar que el hijo usaría esas herramientas a favor del pa-

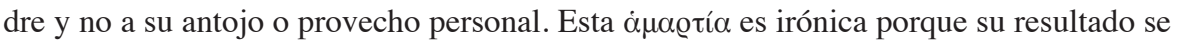
vuelve contra él exactamente del mismo modo en que él planeaba ultrajar a los demás". 
veces niños; y es más verosímil que los viejos lloren y no los jóvenes, en la medida en que es menos razonable que ellos cometan faltas. ${ }^{13}$

De tal manera, el joven Fidípides ha aprendido a argumentar en el

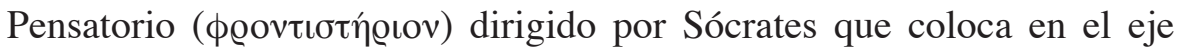
de la discusión un hecho verosímil y, por lo mismo, refutable: el modo como educan los padres a los hijos, en cuya discusión cabe disponer las mismas premisas para ambos sujetos. ${ }^{14} \mathrm{Si}$ el padre por ser benevolente educa a golpes al hijo, entonces éste debe responder de manera recíproca según el ethos que implica la relación filial; y si se atiende a la circunstancia de la edad, entonces el padre es dos veces niño por su vejez, por lo que merece doble benevolencia, esto es, dos veces más golpes, pues sus faltas también serían dobles porque ha vivido más que el hijo y, por lo tanto, tendría mayor experiencia. Esta forma argumentativa puede mirarse desde la perspectiva de la analogía: por la vía de un concepto ético, en este caso el ser benevolente (घủvoeîv), es lícito pensar en la reciprocidad del acto educativo, esto es, que padre e hijo se golpeen mutuamente para aprender, proceso complejo que se genera a partir de que se tiene en consideración lo que resulta mejor para uno y para otro paradójicamente. El argumento es verosímil porque el hijo disputa al padre sobre la base de sus mismas premisas, disponiéndolas para su provecho. Además, esta igualdad no sólo obedece a la relación filial, sino también a la simple razón de que ambos son seres libres por naturaleza (₹̌ $\phi v v$ $\dot{\varepsilon} \lambda \varepsilon v \dot{\theta} \theta \varepsilon \circ \varsigma)$, y por lo tanto con libertad para razonar. Llama la atención el término que alude a la "naturaleza" porque Estrepsíades responde a su hijo que "en ningún lado se estipula (por ley) que el padre padezca

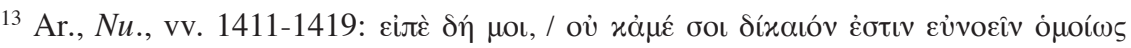

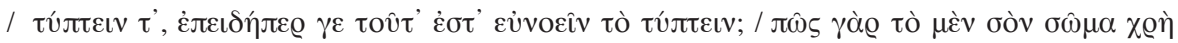

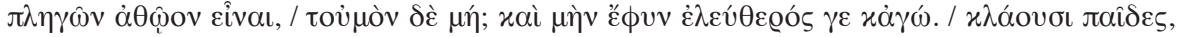

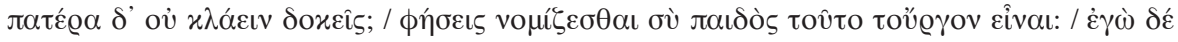

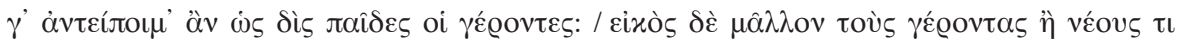

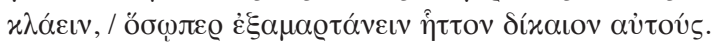

${ }^{14}$ El plan para educar a Fidípides falla totalmente. Zimmermann 2006, p. 246: “Als Strepsiades nach dem 2. Agon, der Auseinandersetzung mit seinem Sohn Pheidippides, bei dem die sophistisch-sokratische Ausbildung allzu großen Erfolg gehabt hat, einsehen muß, daß sein genialer Plan, mit Hilfe von Dialektik und Rhetorik die Schulden loszuwerden, die sein mißratener Sohn aufgehäuft hat, kläglich gescheitert ist und sich gegen ihn selbst gerichtet hat, wendet er sich mit anklagenden Worten an den Chor der Wolken (1452-1464)". 
eso", ${ }^{15}$ esto es, que no está considerado legalmente que el hijo golpee al padre por benevolencia (educativa). Si esto es así, nos hallamos ante una discusión que coloca en los opuestos a la physis y al nomos como sustratos de argumentos verosímiles. En este punto, la coincidencia de Aristófanes con la tragedia es clara en cuanto al debate entre estos dos conceptos enfrentados, pues se trata de una discusión que ocupó parte del pensamiento filosófico de los siglos V y IV a. C., mismo que se reflejó en el teatro ateniense en tanto que fue una preocupación que transitó más allá de la mera especulación. Si bien se sostiene que la ley natural (physis) es base de la ley humana (nomos) y que incluso en un momento dado encuentran un equilibrio, en el caso de Fidípides y Estrepsíades es motivo claro de disputa que parece no tener una conclusión adecuada con la norma tradicional: ${ }^{16}$

FIDíPIDES: ¿Acaso no fue un hombre como tú y como yo el primero que puso esa ley, y hablando persuadía a los antiguos? ¿Y es que yo por mi parte tendré menor posibilidad de poner una ley para que los hijos en el futuro golpeen también ellos a sus padres? No contaremos los golpes que recibimos antes de que estuviera dispuesta la ley y les concedemos habernos molido a golpes impunemente. Mira los gallos y esos otros animales, cómo se cobran de sus padres. Y bien ¿cuál es la diferencia entre nosotros y ellos, a no ser que no escriben decretos? ${ }^{17}$

La dimensión y los alcances de la ley es el objeto de la discusión en torno al comportamiento del hombre. La educación retórica funda una controversia en torno a la naturaleza misma de la norma social no sólo para el estricto ejercicio de la erística, como puede ser el caso que caracteriza el proceder de Fidípides en el terreno de una cuestión familiar, sino también como un medio de profunda reflexión con el que se pretende llegar a la definición de la ley humana y de la ley divina, en tanto

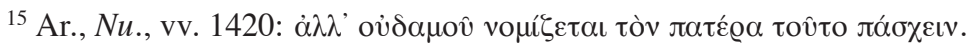

${ }^{16}$ Cf. Nussbaum 1979, pp. 63 ss.

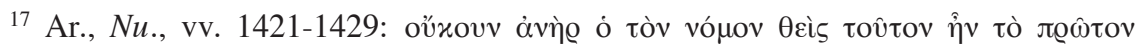

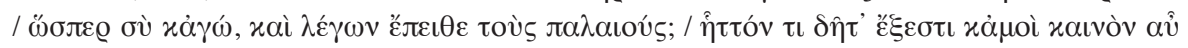

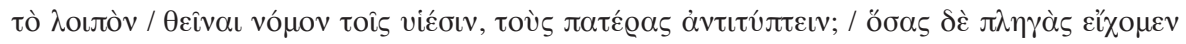

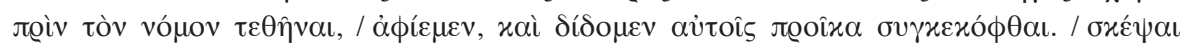

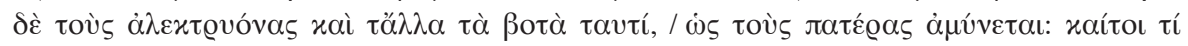

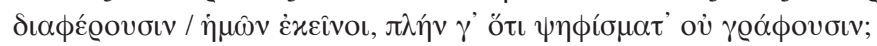


que presentan procesos y fines distintos en última instancia, tal como lo expresa Antígona dirigiéndose a Creonte:

ANTíGOna: No pensaba que tus proclamas tuvieran tanto poder como para que un mortal pudiera trasgredir las leyes no escritas e inquebrantables de los dioses, que no son de hoy ni de ayer, sino de siempre, y nadie sabe cuándo vieron la luz. No iba yo a ser castigada por ellas de parte de los dioses por miedo a la intención de hombre alguno. ${ }^{18}$

Si el ser humano se diferencia del resto de los animales por poseer el lenguaje, entonces él mismo puede hacer la distinción entre lo que es bueno y lo que es malo, entre lo justo y lo injusto, del mismo modo que puede transmitir sus sentimientos y pasiones a otros hombres a través de la palabra. Esto lo convierte en un ser racional y capaz de convivir dentro de una comunidad. ${ }^{19}$ Sin embargo, se puede decir que la posesión de la palabra es el primer paso que asienta el proceso de enseñanza del lenguaje que lo faculta para hablar. La palabra por sí misma no es razón suficiente para determinar la capacidad que el sujeto tiene para comunicarse; el punto siguiente, para decirlo en breve, es el de aprender a usar

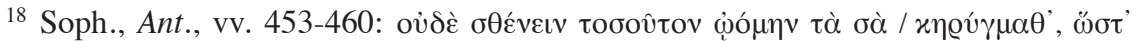

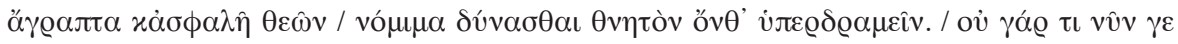

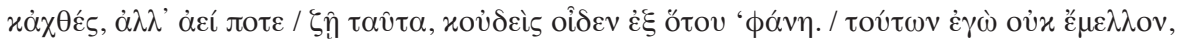

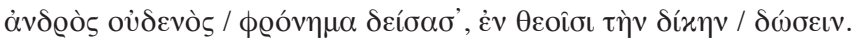

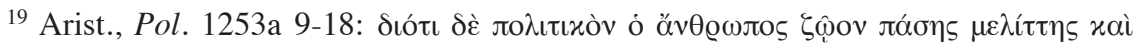

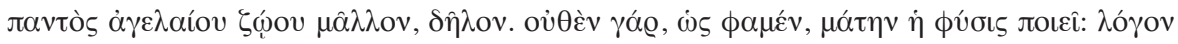

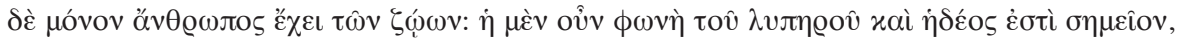

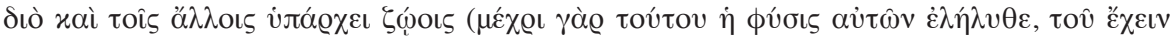

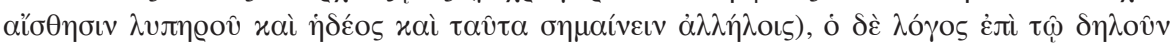

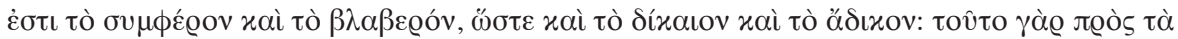

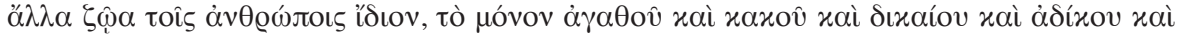

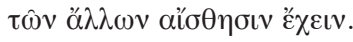

Quizá Las bacantes sea la tragedia que muestra la dicotomía nomos-physis en su sentido más trascendente en el marco de la tragedia, pues el mundo regido por las leyes de los hombres es puesto en un examen de dimensiones religiosas y cosmológicas con la irrupción de Dioniso (la physis) en ese espacio. Segal 1982, p. 346: "Euripides shows the liberating forces of Dionysus as destructive when they have to dissolve narrow constrictions upon life energies. Here Dionysus will act through the subversive power of play and deception, akin to the playfulness of art and the fictions of the poet. But these playful, fiction-indulging, illusion-casting roles have a concomitant positive side insofar as they also participate in the energies of creation". 
la palabra, a crear argumentos para disponerlos frente a otro sujeto y disponer de recursos para persuadir. ${ }^{20} \mathrm{La}$ implicación de dicho aprendizaje es lo que se puede condensar en la idea de una filosofía del lenguaje: la retórica. Esta especie de instrucción se presenta como una invención en el contexto de Aristófanes, tal como lo plasma en Nubes, pues Estrepsíades piensa que su hijo aprenderá la manera de argumentar lo bueno y lo malo asistiendo al Pensatorio, una escuela estrafalaria por sus ideas astronómicas, ${ }^{21}$ entre otras características:

Estrepsíades: De las almas sabias ese es el Pensatorio. En tal lugar moran hombres que mueven a pensar con sus palabras que el cielo es un brasero que nos contiene, y que somos nosotros los carbones. Ellos enseñan, si se les da algo de plata, cómo ganar las causas buenas y las malas mediante discursos. ${ }^{22}$

La enseñanza se torna ya en una actividad profesional y los foros públicos eran espacios donde se practicaba y se aprendía a utilizar la palabra. En este sentido el teatro de la antigua Atenas tuvo una proyección e influencia determinante en el aprendizaje retórico de aquellos que asistían a las representaciones escénicas. La crítica aristofánica, no obstante su acritud, indica esta circunstancia en varios pasajes de su obra: en $R a$ nas vv. 674 y ss., se lee que "la gran concurrencia del gentío" (

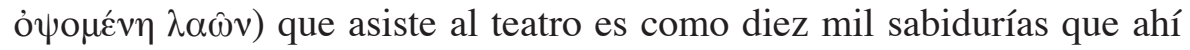

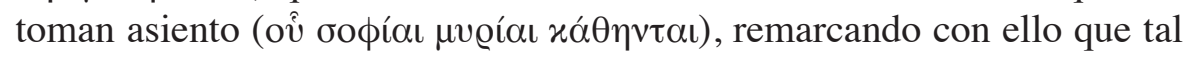
muchedumbre se asume como ente sabio por asistir al teatro; Praxágora, la protagonista de Asamblea de mujeres, aprendió a hablar tan persua-

${ }^{20}$ Sobre la conciencia que el griego de época clásica tenía sobre el valor, la potencia y aplicación de la palabra, cf. Aesch., PV., vv. 459 ss., Soph., Ant., vv. 354 ss., Isoc., Ant., 167 ss. López Eire 2005, p. 14: "Como el hombre es un animal político-social que posee el lenguaje para mantener relaciones de índole psicológica con sus semejantes, con sus conciudadanos [...] para transmitirse mutuamente y compartir la «sensación» [...] del bien, del mal, de lo justo y lo injusto, para «hacer ver» [...] a sus conciudadanos lo conveniente y lo perjudicial, lo justo y lo injusto, el lenguaje debe estar dotado para tales funciones".

${ }^{21}$ Sobre la burla a la filosofía, en general, y Sócrates, en particular, cf. Schmid 1948, pp. 209-228.

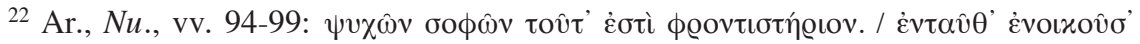

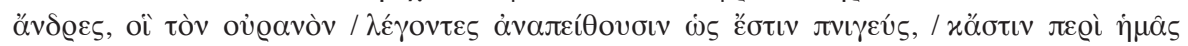

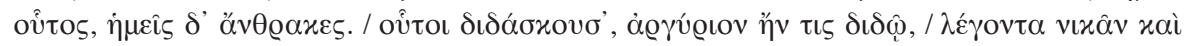

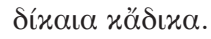


sivamente como aquellos que intervenían en la Asamblea porque vivió en la Pnix, la colina que se halla cerca del Areópago y de la Acrópolis, donde se reunían los ciudadanos atenienses para dirimir los asuntos de la polis, "y a fuerza de escuchar a los oradores" aprendió a hablar como

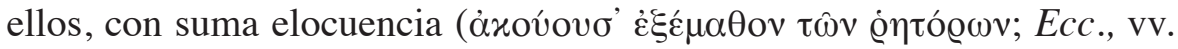
241 ss.); y en Acarnienses (vv. 1-42), Dicéopolis arremete contra quienes no llegan a tiempo a la Asamblea para tratar un asunto tan trascendente como el de la paz y, mientras espera, se prepara e imagina de que manera gritará "para interrumpir, para reprender a los oradores, si alguien habla de alguna otra cosa que no sea la paz". ${ }^{23}$ Estos ejemplos indican en cierta medida que la gente común y corriente estaba al tanto de las funciones del lenguaje como vehículo para alcanzar un determinado fin. Y hay que acotar que se trata de un ejercicio retórico que se daba, como señala Aristóteles, ya sea por naturaleza o porque había una práctica nacida en la teoría, ${ }^{24}$ lo que proporciona una idea de cuán extendida estaba en los siglos v y IV a. C. la discusión sobre el mismo arte de la retórica.

Así como Praxágora aprendió retórica escuchando a los políticos, ${ }^{25}$ del mismo modo se puede establecer una analogía con los asistentes al teatro: este espacio fue la otra gran escuela pública en la que se aprendía a argumentar, incluso desde una perspectiva lógica y no meramente verosímil. Eurípides, como personaje de Ranas afirma: "yo en persona los conduje [sc. a los asistentes al teatro] a tener razonamiento en sus mentes al introducirlos en el arte del cálculo racional ( $\lambda \circ \gamma \iota \sigma \mu o ́ \varsigma)$ y de la indagación, de modo que reflexionan sobre todo y son capaces de discernir" ${ }^{26}$ Aristóteles en su Retórica quizá recupera de un pasaje como este de Aristófanes sus observaciones sobre el cálculo racional, una operación lógico-argumentativa propia de la persuasión, pues hay, sin duda, un vínculo con la idea de que las acciones que lleva a cabo el

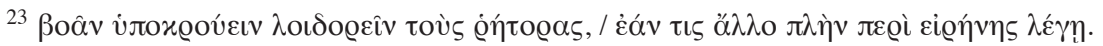

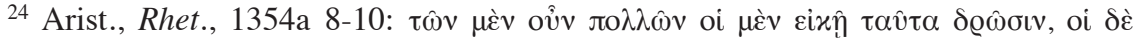

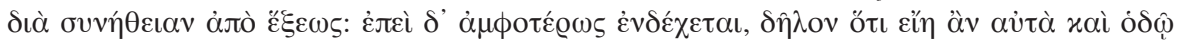

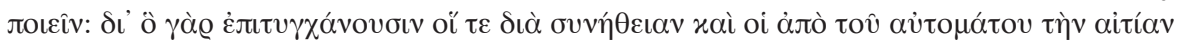

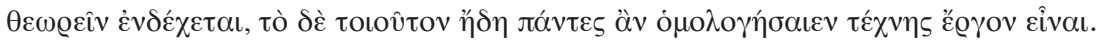

${ }^{25}$ El ejercicio político de la mujer era una parodia en virtud de lo risible que para los atenienses de la antigüedad resultaría que hablara políticamente y lo hiciera bien, y que tratara de dirigir la polis. Cf. Bañuls Oller 1997, pp. 43-62.

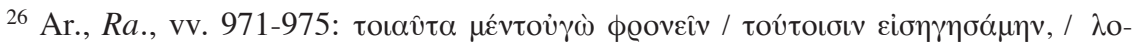

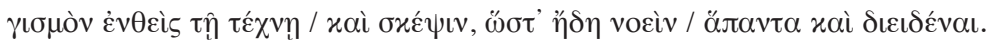


ser humano se ejecutan, entre otras cosas, por medio del logismós, ${ }^{27}$ tal como ocurre con los personajes de Eurípides, como Medea o Electra, ${ }^{28}$ quienes llevan a cabo sus planes con el absoluto conocimiento de causaefecto y argumentan para el público las razones (calculadas) por las que cometen sus respectivos asesinatos. $\mathrm{Y}$ en este proceso el tejido retórico juega un papel primordial: en general, la muerte en las tragedias de Eurípides está aderezada con argumentos retóricamente verosímiles para que el público no sólo padezca, sino también escuche las razones ciertas o no que mueven a los personajes trágicos a situaciones extremas.

En el pasaje señalado de la retórica aristotélica, el logismós es una de las siete causas por las que el individuo comete injusticia, hecho sobre el que se debe reparar, porque en un proceso judicial, de acuerdo con Aristóteles, ${ }^{29}$ el acusador y el defensor deben de reconocerlas a fin de saber ponderar la naturaleza de la injusticia: estamos frente a un proceso retórico que involucra un análisis de la razón por el que un individuo se comporta injustamente. ¿Qué tiene que ver esto con la persuasión? Algunas de las seis causas restantes tocan más directamente a la tragedia: el azar, la naturaleza, la fuerza, el hábito, el apetito irascible y el deseo pasional. Como se puede observar, dentro del conjunto de causas por las que se comete injusticia sólo el logismós corresponde a una estructura y a un contenido que alude a un procedimiento lógico-formal, mientras que el resto es propio de los campos del ethos y del pathos, si seguimos la proposición aristotélica ${ }^{30}$ acerca de las fuentes o de los receptores de los argumentos que se construyen a partir de éstos.

El señalamiento puntual de Aristófanes a la tragedia euripídea como un medio de educación para el demos era un hecho real en la representación de las tragedias en la medida en la que se puede comprender cómo los receptores aprendían de la poesía los modos de expresar la pasión, el carácter y el pensamiento en sí mismo, así como la dicotomía de lo justo y de lo injusto, y de los tópicos que se derivan de ésta. Quizá en este

${ }^{27}$ Cf. Arist., Rhet., 1369a 6 ss.

${ }^{28}$ Cf. Bers 1994, pp. 176-195.

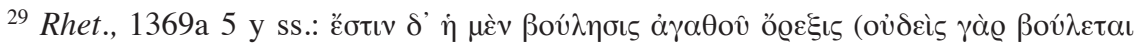

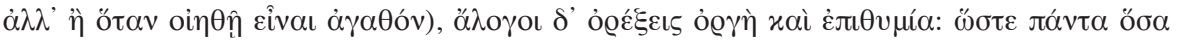

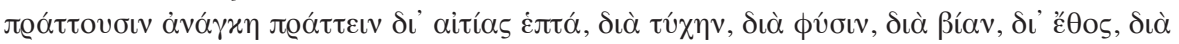

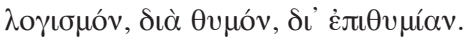

${ }^{30}$ Para el ethos como fuente de persuasión que parte del orador, cf. Rhet., 1356a 5 ss. De igual modo, para el pathos, cf. 1382 b 30 ss. 
sentido, Ateneo formuló, al hablar de eros y poesía, la idea de un Eurípides visto como "filósofo de la escena", ${ }^{31}$ esto es, más allá de la labor teatral propiamente dicha. Este poeta puso en el escenario la disquisición sobre aspectos de la naturaleza humana que trascendieron los planos de los personajes épicos en acción a la manera de Esquilo y de Sófocles, si vinculamos esta breve referencia con la crítica aristofánica de Ranas.

Sin embargo, se puede observar que al menos en el aspecto temático hay puntos de contacto evidentes entre Aristófanes y Eurípides que adquieren cierta proyección en el plano de la educación. Como poetas, ambos llevan en sus versos aquel material propio de debate que permitía al auditorio reflexionar sobre las propuestas desarrolladas en el escenario. Su comedia y su tragedia, respectivamente, hacían eco de las más variadas discusiones que se perfilaban en su contexto, y dentro de estas la idea de una educación pragmática ocupó sus reflexiones en varios momentos.

Si bien es cierto que Aristófanes a través de un personaje cómico como Fidípides lanza una diatriba contra el magisterio retórico de los sofistas y censura en Ranas el que Eurípides enseñara a hablar al de$m o s$, es posible trazar una analogía con este tipo de educación - por los aspectos retórico y filosófico - con el despliegue etopéyico, patético y lógico de la Electra de Eurípides. Si Fidípides argumenta por verosimilitud el carácter potencial de la paternidad, Electra, de modo semejante, razona las causas por las que Clitemnestra debe morir, desconociendo en términos prácticos a su progenitora: en ambos casos, la argumentación puesta al servicio del desconocimiento de los padres. Aparentemente en oposición, el despliegue dramático de Fidípides y de Electra — cada uno en su campo dramático de acción - es prueba de una educación retórica con fines claramente pragmáticos. En efecto, en Electra se halla un explícito caso en el que la retórica acompaña a la acción dramática en sentido amplio. Tal entramado es reflejo del perfil trágico de este personaje. Así como Fidípides entra en liza contra su padre a causa de que no quiere defenderlo ante sus deudores y, al contrario, deviene en su enemigo como consecuencia de las enseñanzas de Sócrates, ${ }^{32}$ del mismo modo, pero en tono trágico, Eurípides presenta a Electra como un per-

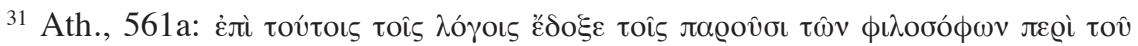

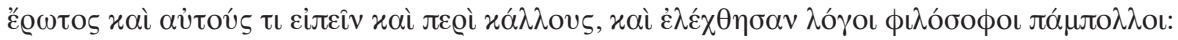

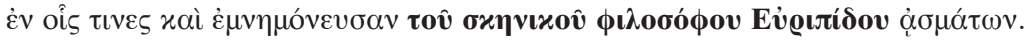

${ }^{32}$ Para un estudio de la crítica aristofánica a Sócrates, cf. Rossetti 1974, pp. 131-136. 
sonaje que argumenta el odio que edifica y sostiene su razón de vivir: su obsesión es tal que, como una odiosa Erinia, sólo existe para atizar el rencor que sentía contra sus enemigos; y sólo ante la muerte consumada de los amantes, la doncella reflexionó sobre el sentimiento que la había acogido y la había guiado en sus acciones, no porque estuviera arrepentida, sino porque a la postre mira lo que es su vida en perspectiva con los afectos de su madre: “¡Pobre de mí! Me consumí en fuego contra

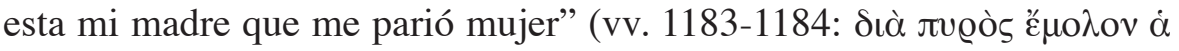

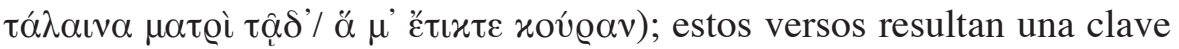
para comprender la naturaleza de la oposición entre madre e hija como una situación esperable del destino, dejando de lado cualquier otra motivación. ${ }^{33}$ Desde el punto de vista meramente argumentativo, las razones que plantean Electra y Clitemnestra sobre el hecho concreto de la muerte de Agamenón son muestra de un ejercicio retórico que se desplegaba en el escenario por medio de oposiciones verosímiles encaminadas a mover las pasiones de los asistentes al teatro por medio del logismós, por paradójico que parezca, esto es, llevar al movimiento de los sentimientos mediante de una argumentación cuasi-lógica. Si todo lo anterior es así, entonces se puede afirmar que las formas de ser y las pasiones son componentes que se despliegan a través de la palabra en el teatro como consecuencia de una teorización del ethos y del pathos, de modo semejante como se estipula en la retórica la teoría de la persuasión.

Siendo esto así, vale la pena contrastar esta situación con el núcleo trágico expuesto en Medea y lo que puede enseñar en el marco teatral. Este personaje es paradigmático en cuanto a la situación extrema de la condición femenina en el contexto ateniense del s. v, pues en ella se presenta una triple negación del ser: como extranjera, como hechicera y como mujer en sí. Y estas tres características conducen a la figuración de un ser inteligente, pensante, lo que choca frontalmente con el imaginario de lo sexual y la dominación que ello conlleva en la Atenas democrática, ${ }^{34}$ de modo semejante pero con el fuerte matiz cómico de

${ }^{33}$ Loraux 1999, p. 54: "Électre est jeune fille, elle est interminablement en deuil de son père, et organise sa vengeance, semblable aux Érinyes dont, à sa dimension, qui est celle d'une mortelle, elle est en quelque sorte una imitatrice. Et, comme les déesses vengeresses, elle est sans fin associée à l'aeí [...], sans compter les moments où Clytemnestre détourne cet adverbe à son propre usage".

${ }^{34}$ Sobre el imaginario sexual y la relación entre Eurípides y Aristófanes sobre este tópico, cf. Craik 1990, pp. 2-3; 11-12. De modo simple: Lisístrata es una mujer que, al 
Lisístrata o de Praxágora. Si de suyo el conocer es trágico, en una mujer lo sería mucho más, desde la perspectiva que define el imaginario de los papeles sexuales y, por extensión, propios de una educación de aquella sociedad. Si Jasón comprende a Medea como mujer, bruja y extranjera, ella, a su vez, siguiendo el patrón del imaginario masculino definiría para su ser lo siguiente: 1) la mujer no puede repudiar al marido sin acarrearse su propia perdición; 2) la esposa debe ser una suerte de adivina para saber qué es lo que mantendría contento al esposo; 3) la mujer está reducida al espacio del hogar, dentro del cual su único referente es el marido. Suponiendo que las premisas y los indicios anteriores parten de la postura de lo masculino que mira, irónicamente, la comodidad de la mujer, la conclusión de Medea es fulminante por irrecusable: “¡Obtusos! Que tres veces con un escudo / preferiría estar a pie firme, que parir una sola vez". ${ }^{35}$ Se puede observar que, en el caso de Medea no hay ni aceptación ni resignación por lo que se refiere a la condición de su ser que se evidencia desde lo que ella rechaza, lo cual se concreta en su actuar, específicamente en el asesinato de sus propios hijos, en aras de castigar a Jasón. Asumiendo literalmente las cualidades que le atribuye éste, Medea actúa y confirma su ser ante la adversidad de las condiciones que externamente la han determinado.

La persuasión ejercida sobre el público que una mujer imaginaria como Lisístrata o Praxágora podía llevar a cabo, tiene su referente en la trama de lo privado y con la gravedad de la tragedia en el despliegue argumentativo de algunos personajes euripídeos como Medea, Ifigenia o Electra: los argumentos de este último personaje, por ejemplo, son motivo de persuasión y, al mismo tiempo, crean una tensión in crescendo hasta arribar al momento en que palabra y acción van de la mano en estrecho compás: la potencia - la dynamis, de acuerdo con Aristóteles - ${ }^{36}$ de la representación adquiere un relieve trágico intenso cuando la palabra se refuerza con la actuación patética, pues "en el agón se adaptan

emancipar la política, logra colocarse en las mismas condiciones del varón; Medea, personaje trágico, no puede obrar como Lisístrata, por lo que recurre a las cualidades que la condenan, según el imaginario griego, y sólo desde esa trinchera puede vengarse, pero no lograr la emancipación. ¿Qué muestra el teatro en esta dicotomía? La situación de la mujer sólo sirve de contraste para agudizar el sentido cómico o trágico del statu quo.

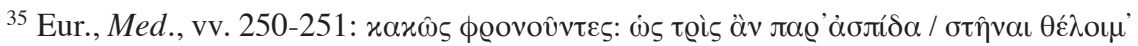

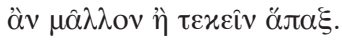

${ }^{36}$ Arist., Po., 1447a 8-9. 
elementos de la representación teatral, de aquí que, al prescindir de tal representación, [los discursos] resultan lánguidos porque no cumplen su cometido". ${ }^{37}$ La tensión se intensifica si se observa como ejemplo que Clitemnestra desconoce el plan de Electra y que morirá indefectiblemente a manos de sus hijos. Las palabras de Electra son premonitorias, porque Clitemnestra no sabe lo que pronto ocurrirá, en realidad el tejido de la persuasión se realiza para matizar o dirigir las pasiones de los espectadores, pues, pasado el golpe dramático, pueden llegar a ser reflexiones sobre el proceder humano, esto es, los asistentes pueden calcular la validez e intensidad del matricidio, como en este caso, pero en general de cualquier pasión catártica: Eurípides establece un puente discursivo entre ethos y pathos, por un lado, y el logos, por el otro. En efecto, el asesinato de una madre a manos de sus hijos debe ser atenuado, en tanto punto álgido de la acción trágica y en virtud de la situación pavorosa que ello comporta. Por esta razón, los argumentos de Electra son verosímiles en lo que se refiere al uso del ethos y del pathos, sin perder por esta cualidad su naturaleza lógica, lo que es, según nos parece, un caso magistral en el que retórica y tragedia se entrelazan. Además, la argumentación de Electra funciona para la justificación de sus actos y para que el juicio de los espectadores sea paliado en relación con el matricidio. Diego Lanza explica así este proceso de argumentación cuando se presentan situaciones semejantes a la descrita aquí respecto de Electra:

Se trata, sin embargo, de paliativos en cierta manera extrínsecos a la historia trágica, compensatorios de la emoción que recién ha padecido el espectador: él, el espectador, primero fue conducido lejos [de sí], siguiendo de otra manera aquello que se representaba, para mirar con otros ojos, para vivirlo con otro espíritu..$^{38}$

De otro modo, ante la evidencia incontrovertible del asesinato de Clitemnestra, los argumentos de Electra serían tan débiles que la estrategia

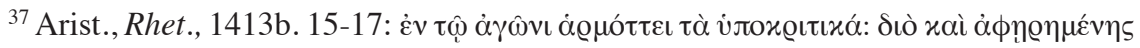

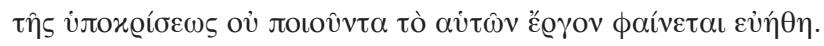

${ }^{38}$ Lanza 2007, p. 74: "Es tracta, però, de tranquillitzacions en certa manera extrínseques a la història tràgica, compensatòries de l'emoció que acaba d'atènyer l'espectador: Ell, l'espectador, primer ha estat portat lluny, a seguir d'una altra manera allò que li representaven, a mirar-ho amb altres ulls, a viure-ho amb un altre esperit". 
consiste en hacerlos verosímiles para remontar la potencial oposición de los espectadores, hecho que aparece de manera semejante en cuanto a la estrategia retórica seguida en Orestes, en el momento en el que el pueblo argivo condena a los homicidas. El ejercicio retórico aquí consiste en hacer del argumento débil el que debe triunfar, sabiendo la desventaja que se tiene ante una evidencia concreta o algún otro argumento más fuerte en torno a la disputa entre physis y nomos. Sobre el argumento débil y el fuerte esto es lo que señala Aristófanes como materia educativa:

Estrepsíades: Para los que asisten [al Pensatorio], dicen que imparten dos clases de discursos: el más fuerte, cualquiera que sea, y el más débil. Con el segundo de estos dos discursos, el más débil, dicen que pueden ganar las causas más injustas. Así pues, si por mí aprendes ese discurso injusto, de aquellas deudas que por tu culpa debo, no pagaré un solo óbolo. ${ }^{39}$

Pero el Pensatorio puede ser una metáfora del teatro, pues también es escuela de retórica, aun cuando no se trata de algún programa llevado a cabo por algún sofista. Nubes, como ejemplo de esto, expone la disposición argumentativa de una causa presentada con sus dos rostros, el justo y el injusto, que devino en la tradición retórica también en sí mismo en un lugar común. Aristófanes relaciona el argumento justo con la educación "antigua", en la que los niños aprendían música, gimnasia y "buenas costumbres". El toque cómico en la totalidad del discurso justo, pero quizá no exento de cierta razón, sintetiza tal educación de este modo:

Argumento Fuerte: Si haces las cosas que te digo y diriges tu atención a ellas, tendrás siempre un pecho brillante, la piel lustrosa, hombros enormes, lengua corta, el culo grande y el pene pequeño. ${ }^{40}$

La "nueva" educación está representada por el discurso injusto, aquel que contradice las normas y que hace que el argumento débil triunfe, con

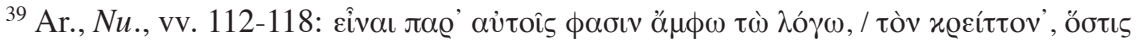

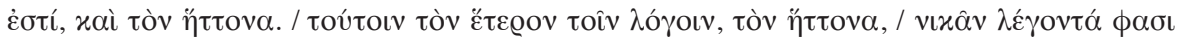

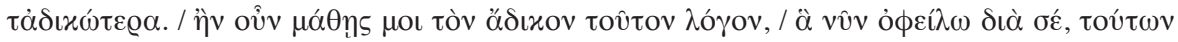

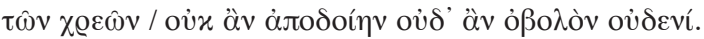

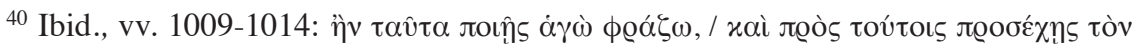

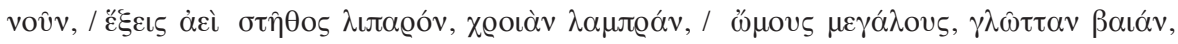

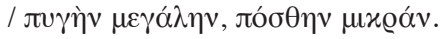


lo cual el orden de las cosas se altera y hace que se pierdan las "buenas costumbres". ${ }^{41}$ El tópico en esta parte de Nubes es la educación (paideia, paideusis) como preocupación intelectual y social, colocando en contradicción la educación tradicional y la educación de los sofistas. La síntesis, representada en la disposición física del sujeto ${ }^{42}$ y que matiza el carácter juicioso de este pensamiento en el marco de lo cómico, es la siguiente:

Argumento Fuerte: Pero si practicas las cosas de ahora, en primer lugar tendrás la piel amarillenta, los hombros pequeños, el pecho reducido, la lengua larga, el culo pequeño, el pene grande y el decreto largo, y él [sc. el argumento injusto, al que señala] te seducirá para que consideres bello lo que es ruin y ruin lo que es bello, y por si fuera poco te pervertirá para que sodomices a Antímaco. ${ }^{43}$

Si bien Estrepsíades considera en un primer momento que dicha enseñanza retórica es positiva por el beneficio personal que puede obtener, pues aprendiendo a argumentar se libraría de sus deudas, ${ }^{44}$ detrás de dicho parecer está la socarronería aristofánica, ya que lo expresado por el padre de Fidípides es en sí un tipo de razonamiento doble en virtud de que el aprendizaje del joven será tan efectivo que se volverá contra las palabras de su propio padre, demostrando el carácter doble de todo argumento. Debe observarse que, al ser una comedia, el tono de Ranas exagera el contenido retórico del argumento; en cambio, el tono serio como corresponde a la tragedia, ${ }^{45}$ manifiesta la viabilidad de que la contingencia argumentativa sea aceptable y recomendable en asuntos de gravedad. Por ejemplo, al saber que los argivos han condenado a muerte a Orestes (vv. 729 ss.), en la tragedia homónima, por la muerte de su madre, éste calcula la posibilidad de hablar para exponer que su causa es

${ }^{41}$ Newiger 1957, pp. 134-143.

${ }^{42}$ Recordemos que la educación griega se dirigía a la unidad cuerpo-mente, según el concepto kalokagathia. Cf. Jaeger 1962, ad locum.

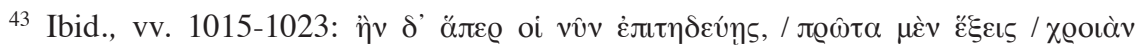

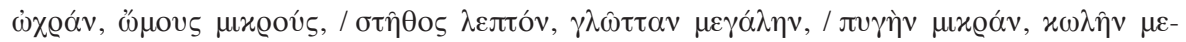

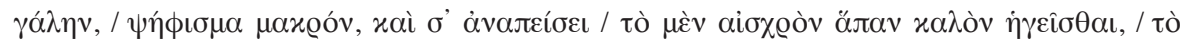

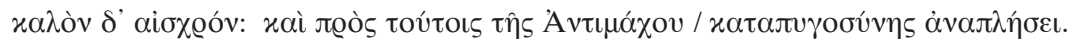

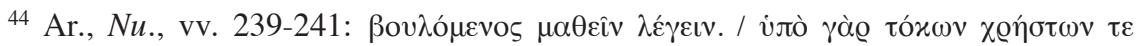

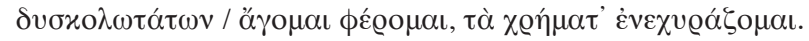

${ }^{45}$ Arist., Po., 1449b 24. 
justa, a lo que Pílades le responde: "Ruega sólo que lo parezca" (v. 783:

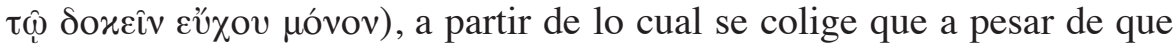
a Orestes le puede asistir la verdad, su dicho en realidad es débil frente a la evidencia que el pueblo ha tomado en consideración para su condena. Si esto es así, la verdad que le asiste a Orestes no es necesariamente el fundamento del argumento fuerte y, antes bien, daría la impresión de no ser lo suficientemente persuasivo para modificar el sentir popular. Lo expuesto por Aristófanes en cuanto a las dos clases de argumento

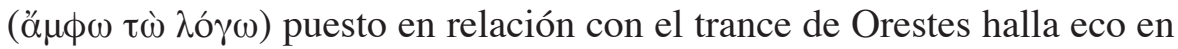
la visión de una misma causa frente a la voluntad del pueblo: Pílades ha sido condenado por su padre por ayudar a su amigo, por lo que Orestes piensa que hay peligro de que también a él lo condenen los argivos, a lo que aquél contesta que en todo caso le corresponde hacerlo a los focenses, su pueblo. Sin embargo, se evidencia que "la muchedumbre es

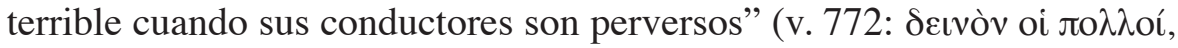

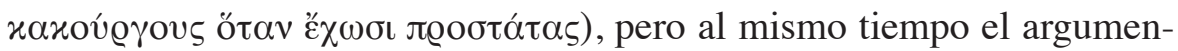
to contrario es válido: "pero cuando los tiene buenos siempre toma de-

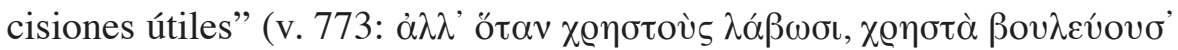
$\left.\dot{\alpha} \varepsilon i^{\prime}\right)$. Como se puede observar, tanto la comedia como la tragedia desplegaban en el escenario las formas argumentativas por vía doble: en el aspecto de lo verdadero y lo falso y, al mismo tiempo, en su carácter verosímil, tomando en este caso la intención de quienes hablan. ${ }^{46}$

Con la seriedad de la trama que impone la Electra de Eurípides, el tejido argumentativo con el que la hija de Agamenón presenta las premisas que justifican su actuar contra los amantes es ejemplo también del modo en que un discurso débil desde la perspectiva de los afectos y las pasiones se torna fuerte con la intención lógica que se imprime a estos mismos. En efecto, siguiendo el orden del discurso de Electra, hay dos partes que corresponden a la narración: Electra, en primer lugar, resume en qué consiste la desgracia gratuita que Egisto cometió contra ella y Orestes: el haberlos privado de su padre al asesinarlo y al haber desposado a Clitemnestra; en segundo término, la doncella abunda en el caso del matrimonio de los asesinos de Agamenón. Efectivamente, en esta parte del discurso se encuentra otro de los giros que Eurípides

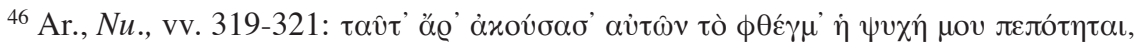

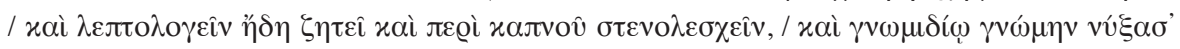

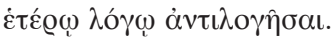


apropió al mito de Electra en relación con su papel de Erinia: si bien la causa que mueve el plan de este personaje es el asesinato de su padre, tal hecho parece quedar en segundo término al momento de poner por delante la relación entre Clitemnestra y Egisto. La intención retórica es evidente: el asesino de Agamenón no sólo ha participado en un delito del todo deplorable, sino que, además, su proceder excesivo llega al punto de robar y corromper a la mujer ajena, por lo que dicha unión es de suyo ilegítima. Así, Electra abona aún más la cauda de argumentos para sostener que la muerte de Egisto es justa, pues su relación con Clitemnestra está viciada por la impiedad que implicó el asesinato y por el espurio matrimonio que es signo de la socavación del oikos, ${ }^{47}$ La alusión que se hace al ataque del oikos es un tópico de primer orden para persuadir al público, porque la esfera de lo privado deviene pronto en asunto público.

Una vez expuesta esta situación, lo que sigue es hacer evidentes las consecuencias del acto injusto, que, por lo ya dicho, debía responderse con un logismós, esto es, con su propia medicina: la primera de ellas es la condición inferior de Egisto frente a Clitemnestra, pues es ésta la que manda en el oikos y determina su composición, lo que significa una subversión del orden social vigente en aquella época: es el varón quien debe gobernar el oikos, no la mujer (vv. 930-937). ${ }^{48} \mathrm{Si}$ lo anterior es así, entonces es posible afirmar que la aristofánica y utópica propuesta de que la mujer es la que debe llevar las riendas del poder, se cumple en el doble papel de gobernante que ejecuta Clitemnestra, pues ella es quien manda en su casa y en su pueblo, en tanto que, desde la perspectiva de esta lectura, Egisto deviene en mera figura decorativa. La segunda

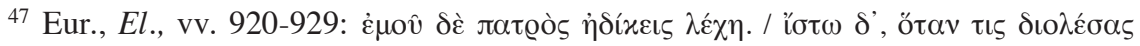

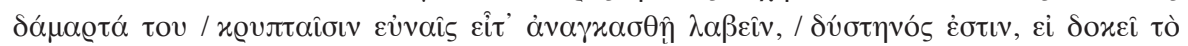

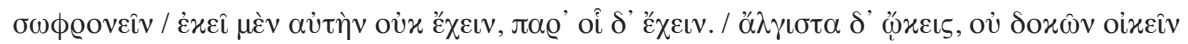

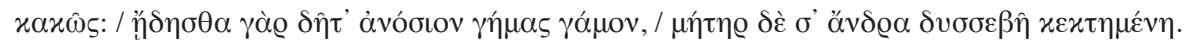

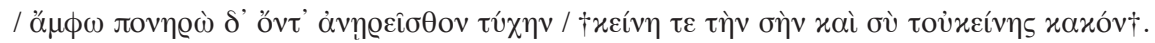

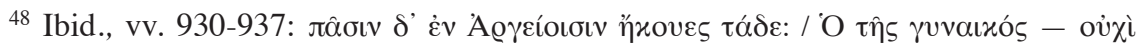

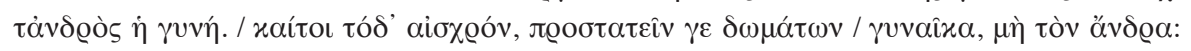

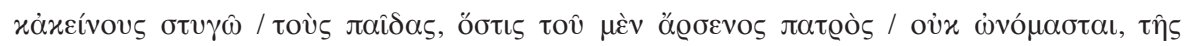

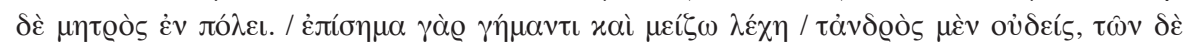
$\theta \eta \lambda \varepsilon\llcorner\hat{v} v \lambda o ́$ os. Praxágora estaría en contra de la argumentación de Electra: paradójicamente ambas mujeres defienden el oikos, pero cada una con diferentes razones. Mientras que Electra pone en evidencia la dominación de Clitemnestra sobre Egisto y, por lo tanto, ella es quien gobierna sin gobernar, Praxágora aboga para que la mujer sea la que gobierne la polis en virtud de que ella es la que manda en su núcleo, el oikos. 
consecuencia está expresada mediante un argumento por comparación: la riqueza ( $\chi \varrho \eta \dot{\mu} \alpha \tau \alpha)$ es efímera y es nada frente a la naturaleza humana ( $\phi v ́ \sigma ı \varsigma)$. Ante este hecho irrefutable, Egisto pierde valía porque apostó su fuerza en la posesión de bienes materiales. ${ }^{49}$ Por último, Electra apunta de modo velado la cobardía de Egisto como otro argumento más para denostarlo. La descripción que hace la doncella recuerda el fragmento $60 \mathrm{D}$ de Arquíloco, donde el poeta lírico pide tener un jefe militar que sea menudo y patizambo, pero valiente, y no uno altivo y bello, pero, según se deduce, cobarde. En efecto, la hija de Agamenón censura al varón de buena presencia, pero que es fingido, "un simple adorno de los coros"

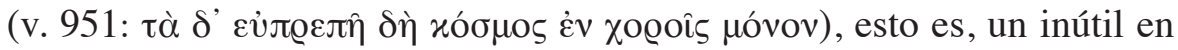
razón de que, según se colige de sus palabras, otra vez por comparación, Egisto es un mero decorado de la casa real a la que tomó furtivamente. El aspecto afeminado de este personaje se halla en correlación con el carácter ajeno a los trabajos de Ares (vv. 945-954), por esto mismo es cobarde, afectado y sometido por una mujer. Tal es la definición del carácter que Electra hace de su enemigo y con la cual persuade a los oyentes en cuanto a sus acciones a fin de sostener la justicia de la acción y de las causas que presenta. En este último tópico vale la pena establecer el siguiente punto de comparación entre la descripción del ethos de Orestes según Electra y la visión educativa del Discurso Fuerte en Nubes. De acuerdo con esta comedia aristofánica, el joven que pretenda seguir la "nueva" educación se convertirá en un ser físicamente débil y afeminado, y con una ética reprobable; de modo semejante, Electra describe a Egisto a partir de la relación de dominio de éste con Clitemnestra. Como se puede apreciar, tanto el discurso cómico como el trágico pueden llegar a una conclusión semejante en torno a un determinado ethos que se presentaba en el teatro bajo estructuras argumentativas.

El breve epílogo del discurso de Electra es una analogía en la que se compara a la Justicia ( $\delta \dot{i} x \eta)$ con un atleta al que se pretende vencer en la carrera o con la meta; en ambos supuestos el elemento no mencionado para completar la estructura es Egisto, quien es el competidor que ya ha perdido porque murió bajo las manos de Orestes (vv. 952-956).

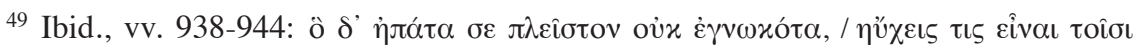

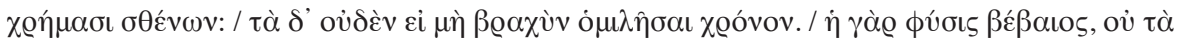

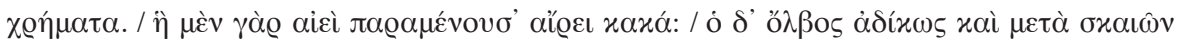

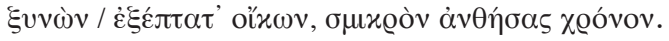


Como se puede advertir, tanto en la comedia de Aristófanes como en la tragedia de Eurípides la oposición de posturas bien diferenciadas sigue la ruta de la antilogía para refutar y dejar sin sustento al adversario, sea en el campo de lo privado como en el de lo público, de tal manera que en el espacio teatral era posible observar cómo el discurso débil se iba haciendo fuerte para llegar a la verosimilitud de las proposiciones en disputa. Sin embargo, vale la pena subrayar que la argumentación de Electra cumple, en el estricto límite, con hacer verosímil su papel de Erinia al fraguar la muerte de su madre y, en cierto sentido, conducir la mano vengadora, pues al final el orden se mantiene incólume con el decreto de los Dioscuros sobre la boda de esta doncella con Pílades. De igual manera, la argumentación de un personaje cómico como Lisístrata, "vengadora" política, se mantiene en el límite de una aceptación social, ${ }^{50}$ pues si bien es cierto que se alcanza la paz entre los pueblos griegos, también lo es que el orden roto por la "más viril de las mujeres" (v.

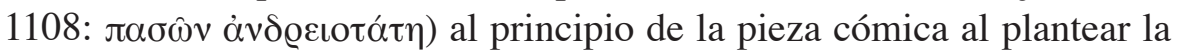

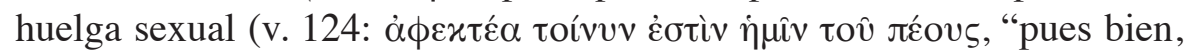
debemos abstenernos del falo"), concluye en una reconciliación —el fin de dicha huelga - y el statu quo anterior se restablece al decir que

cada hombre esté junto a su mujer y cada mujer al lado de su hombre y después, una vez que por estos buenos acoplamientos hayamos danzado en honor de los dioses, cuidémonos de cometer errores nuevos otra vez en el futuro. ${ }^{51}$

No obstante la presencia del ejercicio retórico, de la intención didáctica y de los ingredientes políticos, tanto en la tragedia como en la comedia persiste un orden social que en cierto modo acepta el lenguaje como objeto de estudio que tiene en la poesía — en la misma poesía dramática - una manera de representar la evolución social a partir de estructuras antilógicas que atañen lo privado y lo público. En todo caso,

50 Scarcella 1973, p. 15: "L'ordine gerarchico dei valori mantiene il suo valore: la donna, idra dalle molte texte in questa universalità «maschile», minacciosa eppure allettante, qui non si ammansisce davvero, ché anzi si fa più virulenta, ma non rivela, ora, che il suo proprio volto, cioè le sue proprie colpe, che sono poi le stesse compe degli uomini".

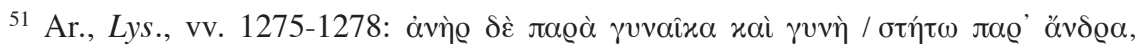

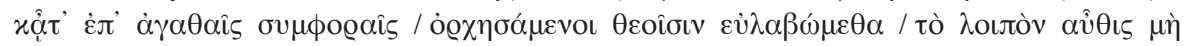

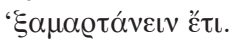


al presentar mujeres elocuentes en el teatro, los poetas sugerirían que el uso de la palabra deviene en una techne (retórica, poética, filosófica) que es propia de todo ser humano. A pesar de su carácter condenatorio, es posible leer también una ironía laudatoria de la inteligencia femenina cuando Medea afirma que las mujeres son incapaces de buenas acciones, pero "artífices muy sabias" de todos los males. ${ }^{52}$ Dejando de lado la discusión sobre la naturaleza de las mujeres, lo expresado por Medea en torno a la comprensión de la sophía como techne revela el cambio que ya había operado en el pensamiento griego al considerar que era posible una paideia "técnica", esto es, con un método mediante el cual era posible llegar a poseer el conocimiento, y en dicho proceso la poesía jugó un papel esencial en un doble camino: por una parte, por sus contenidos en sí como los aquí expuestos y que eran útiles para hacer mejores ciudadanos $^{53} \mathrm{y}$, por otra, porque se tejían referencias a la misma utilidad de la poesía frente a otros saberes, especialmente frente a la filosofía.

$\mathrm{Si}$, como se refiere, Sócrates sólo asistía al teatro cuando se presentaba alguna trilogía de Eurípides y él mismo fue personaje de la comedia, ${ }^{54}$ habría que considerarlo como una figura simbólica en la cual la educación se manifestaba en su doble dimensión, esto es, como retórica y como filosofía, saberes que en un punto dado eran la misma techne, pues sólo a través del lenguaje en su ropaje argumentativo es que se puede dar el ejercicio filosófico (dialéctico, como se puede colegir de la primera definición que se halla en la Retórica de Aristóteles). ${ }^{55}$ La educación superior en la Atenas democrática consistía en gran parte, entonces, en una reflexión sobre las posibilidades que el lenguaje brindaba para nombrar al mundo y construir a partir de él todo aquello que el ser humano era capaz de pensar, de imaginar y de crear. La poesía era un área esencial

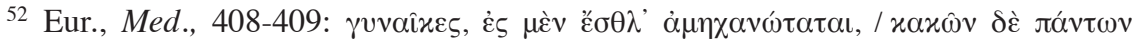

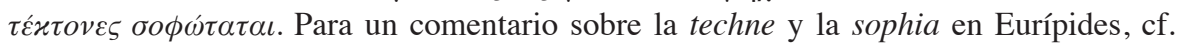
Origa 2007, pp. 14-19.

${ }^{53}$ Cf. supra p. 42.

${ }^{54}$ Por lo menos para la comedia era un tópico la identificación entre Sócrates y Eurípides. Cf. Ar. fr. 392 Kassel-Austin (que procede de la primera versión de $N u$.), Telecleides frr. 39 y 40 (Edmonds), Calias fr. 12 (Edmonds).

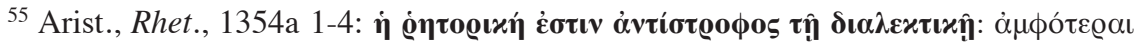

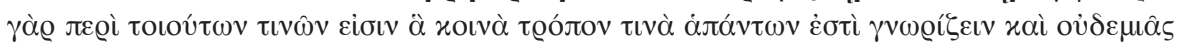

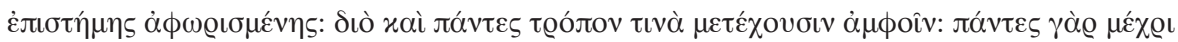

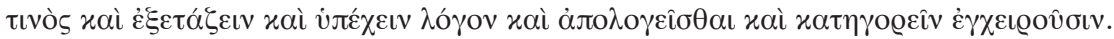


en la formación del individuo de aquella época y en nuestros días debería serlo también, pero la política educativa actual apuesta por la formación pragmática del sujeto para que responda a la maquila y reciclaje de su entorno: úsese y tírese. En la Atenas clásica, la disputa entre una educación "tradicional" y otra "novedosa" tuvo en el teatro un foro de acción en el que los personajes cómicos y trágicos planteaban antilogías en torno a discusiones que tocaban asuntos privados y públicos, la frontera entre éstos se diluía en razón del discurso propiamente poético que matizaba y proyectaba el pensamiento crítico. En suma, es un ideal intelectual que Sófocles reflejó con meridiana claridad en Antígona al hablar sobre las posibilidades del conocimiento del ser humano, quien:

aprendió por sí mismo el lenguaje y el alado pensamiento, así como las civilizadas reglas para comportarse, y también, fecundo en recursos, aprendió a esquivar bajo el cielo los dardos de los apacibles hielos y las de las lluvias inclementes. Nada de lo por venir le encuentra falto de recursos. Sólo del Hades no tendrá escapatoria. De enfermedades que no tenían remedio ya ha discurrido posible evasiones. ${ }^{56}$

\section{BIBLIOGRAFÍA}

ARISTófAnes, Lisístrata, introd., trad. y nts. de Antonio López Eire, Salamanca, Hespérides, 1994.

ARISTOPHANE, Nuées, texte établi par Victor Coulon et traduit par Hilaire van Daele, Paris, Les Belles Lettres, 2009.

-, L'Assemblée des femmes. Ploutos, texte établi par Victor Coulon et traduit par Hilaire van Daele, revue et corrigée par Jean Irigoin, Paris, Les Belles Lettres, 1930. Aristote, Constitution d'Athènes, texte établi et traduit par Georges Mathieu et Bernard Hassoullier, introduction de Claude Mossé, Paris, Les Belles Lettres, 1996. ArISTÓTELES, Retórica, introd., trad. y nts. de Quintín Racionero, Madrid, Gredos (Biblioteca Clásica, 142), 1990.

—, Poética, ed. trilingüe, introd. y nts. de Valentín García Yebra, Madrid, Gredos (Biblioteca Románica Hispánica), 1999.

Athenaeus, The Deipnosophists, with an English translation by Charles B. Gulick, Massachusetts, Harvard University Press, 1961.

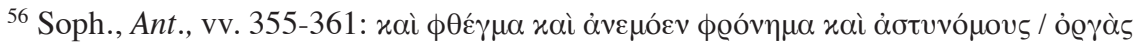

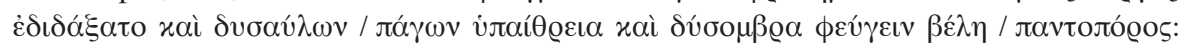

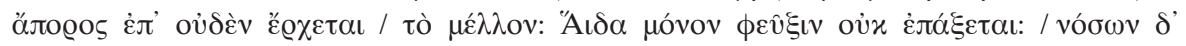

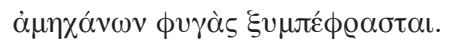


Bañuls Oller, José Vicente, "Mujeres en la voz de mujeres", Quaderns de Filologia. Estudis Literaris, 3, 1997, pp. 43-62.

Bers, V., "Tragedy and Rhetoric", en I. Worthington (ed.), Persuasion: Greek Rhetoric in Action, London \& New York, Routledge, 1994.

Bollack, Jean, "Notes on Tragic Rhetoric in Euripides' Hecuba", en Phillip Mitsis y Christos Tsagalis (eds.), Allusion, Authority, and Truth. Critical Perspectives on Greek Poetic and Rhetorical Praxis, Berlin, De Gruyter, 2010.

Cavallero, Pablo A., "Trygoidía: la concepción trágica de Nubes de Aristófanes", Emerita, LXXIV-1, 2006, pp. 89-112.

Edmonds, John M., The Fragments of Attic Comedy, vol. 2-3, Leiden, Brill, 1957. Esquilo, Prometeo encadenado, introd., trad. y nts. de David García Pérez, México, IIFL-Universidad Autónoma de México, 2013.

EURíPIDES, Electra. Orestes, t. IV, introd., texto revisado y trad. de Antonio Guzmán Guerra, Madrid, CSIC, 2000.

FuMAROLI, Marc, La educación de la libertad, Barcelona, Arcadia, 2008.

Isocrate, Discours, IV vols., texte établi et traduit par George Mathieu y E. Brémond, Paris, Les Belles Lettres, 2003.

JAEGER, Werner W., Paideia: los ideales de la cultura griega, México, FCE, 1962.

Kassel, R. \& C. Austin, Poetae Comici Graeci, 8 vols., Berlin, De Gruyter, 1983.

Laudo Castillo, Xavier, "La hipótesis de la pedagogía posmoderna. Educación, verdad y relativismo", Teoría de la educación, 23-2, 2001, pp. 45-68.

LANZA, Diego, "De l'emoció tràgica, avui", en Maite Clavo y Xavier Riu (eds.), Teatre grec: perspectives contemporànies, Barcelona, Pagès editors, 2007.

LóPEZ EIRE, Antonio, “«Espace public» ou «espace de la communication» dans la comédie d'Aristophane”, Pallas, 54, 2000, pp. 141-190.

- Sobre el carácter retórico del lenguaje y de cómo los antiguos griegos lo descubrieron, México, Instituto de Investigaciones Filológicas-Universidad Autónoma de México (Bitácora de Retórica, 21), 2005.

LORAuX, Nicole, La voix endeuillée. Essai sur la tragédie grecque, Paris, Gallimard, 1999.

Newiger, H.-J., Metapher und Allegorie. Studien zu Aristophanes, München, C. H. Beck, 1957.

Nussbaum, Martha C., "Eleatic Conventionalism and Philolaus on the Conditions of Thought", Harvard Studies on Classical Philology, 83, 1979, pp. 63-108.

ORIGA, Valentina, Le contraddizioni della sapienza. Sophia e sophos nella tragedia euripidea, Tübingen, Gunter Narr Verlag, 2007.

Orwell, George, Animal Farm. 1984, Florida, Hartcourt Books, 2003.

Platon, Protagoras, texte établi et traduit par Maurice Croiset, Paris, Les Belles Lettres, 1923.

—, Théétète, texte établi et traduit par Auguste Diès, Paris, Les Belles Lettres, 1923.

Rossetti, L., "Le Nuvole di Aristofane: perché furono una commedia e non una farsa?", Rivista de Cultura Classica e Medioevale, 16, 1974, pp. 131-136.

SCARCElla, Antonio M., Il messaggio di Aristofane e la cultura ateniese, Perugia, Palumbo Editore, 1973. 
SchMiD, Wolfgang, "Das Sokratesbild der Wolken", Philologus, 97, 1948, pp. 209228.

Segal, Charles, Dionysiac Poetics and Euripides' Bacchae, Princeton, Princeton University Press, 1982.

Sophocle, Tragedies: Les Trachiniennes. Antigone, texte établi par Allan Dain et traduit par Paul Mazon, revue et corrigée par Jean Irigoin, Paris, Les Belles Lettres, 1955.

Zimmermann, Bernhard, "Pathei mathos: Tragische Strukturen in den Wolken des Aristophanes", Studia Philologica Valentina, 9, 2006, pp. 245-253. 
